Desde la Edad Media, los centros universitarios han surgido en el seno de las ciudades históricas de Europa, dejando su impronta no solo en la estructura urbana sino también en el imaginario colectivo. En conjunto con la arquitectura de los poderes eclesiásticos, institucionales y edificios públicos, conforman un paisaje urbano de gran calidad, entrelazando la vida universitaria y la vida ciudadana durante siglos de simbiosis cultural. De esta manera, los efectos de la función universitaria en las urbes las convierten en verdaderas «ciudades universitarias», como Oxford, Lovaina, Rennes, Salamanca, Alcalá de Henares, entre otras.

La Universidad de Alcalá fue creada oficialmente en 1292; sin embargo, en 1499 fue refundada desde una visión reformista, humanista y renacentista. Durante este periodo de reestructuración fue posible concebir un modelo urbanístico adecuado a las necesidades universitarias. A pesar de ello, la universidad fue trasladada a Madrid mientras que la ciudad de Alcalá se transformó en una ciudad militar y los edificios académicos pasaron a ser cuarteles o prisiones. Finalmente, fue refundada en 1977, devolviendo la vida universitaria a la ciudad a partir de la restauración y recuperación de los edificios planificados por el cardenal Cisneros. Además, fue incluida en la Lista del Patrimonio Mundial (1998).

El libro está dividido en dos partes. La primera parte se subdivide en cuatro capítulos. En el primer capítulo se presenta la universidad y su contexto. Se desarrolla el sistema universitario español, el cierre de la Universidad de Alcalá en 1836 y el largo periodo de transición entre 1975 y 1978, que permitió el retorno de la universidad a la ciudad. Asimismo, se bosquejan ideas para optimizar su funcionamiento, reconociendo errores en el proceso de implementación de la universidad.

El segundo capítulo se centra en el campus histórico de la universidad, enfatizando la recuperación de sus edificios emblemáticos, ubicados en el casco antiguo de la ciudad, y el devenir histórico de la universidad: pasó de ser la gran universidad hispánica del Siglo de Oro a estar inmersa en un periodo de cambios, pausas, cierre y retorno, hasta que, finalmente, fue rescatada y, debido a su gestión, devuelve su gran patrimonio universitario a la ciudad y sus ciudadanos.

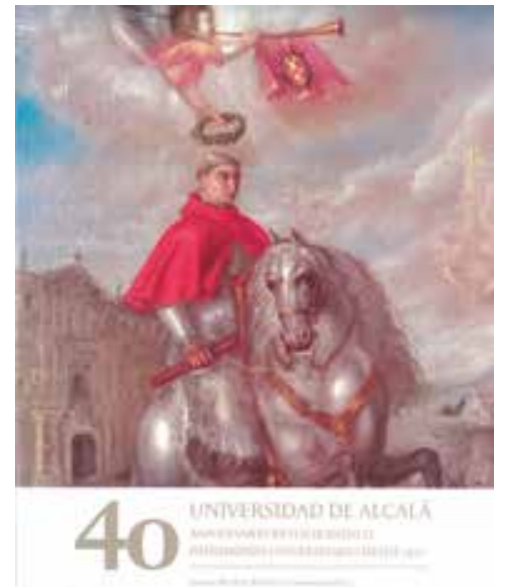

\section{UNIVERSIDAD DE ALCALÁ. 40 ANIVERSARIO RESTAURANDO EL PATRIMONIO UNIVERSITARIO DESDE 1977}

JAVIER RIVERA BLANCO (COORD.]

UNIVERSIDAD DE ALCALÁ, MADRID, ESPAÑA, 2018.

RESEÑA DE MIGUEL MARQUINA PINEDO
En el tercer y cuarto capítulo se muestran las otras dos sedes de la universidad, que se encuentran fuera del casco antiguo: el campus científico-tecnológico, que se encuentra en la periferia, a dos kilómetros del centro histórico de la ciudad, y se plantea como un recinto universitario que alberga muchos edificios académicos y administrativos, además de residencias universitarias, y el campus de la provincia de Guadalajara. Este último es un reto a futuro, pues esta ciudad, de la mano de la universidad, pretende recuperar su patrimonio histórico, tanto el construido como el intangible, lo cual es una apuesta importante de la Universidad de Alcalá.

La segunda parte del libro es una compilación de fotos planos y fichas producidas para ser expuestas en una fecha importante en que se conmemoran cuarenta años restaurando el patrimonio universitario y una celebración por los veinte años de la declaración de la universidad como patrimonio mundial.

El valor de este libro radica en la búsqueda de la identidad de la universidad, que recupera su patrimonio arquitectónico porque el proyecto inicial fue construir un campus externo a la ciudad que permitiera absorber el exceso de demanda universitaria de la capital. No obstante, fue la misma universidad la que propuso la recuperación de su pasado recreando la ciudad universitaria en su totalidad, sin renunciar a un campus moderno en el extremo de la ciudad.

De esta manera, la Universidad de Alcalá presenta un caso emblemático que permite afirmar una vez más que el patrimonio arquitectónico y la cultura académica, que confluyen en los centros históricos de las ciudades, son potenciales perfectamente compatibles y sinérgicos que pueden y deben propiciar su rehabilitación física, revitalización social y regeneración funcional. Esta interesante práctica urbanística-patrimonial ha ratificado que la actividad universitaria es un factor clave para una rehabilitación integrada, pues fomenta la restauración formal (edificios patrimoniales), poblacional (jóvenes residentes), habitacional (vivienda para estudiantes y profesores), funcional (comercial y de servicios) y turístico-cultural creada a partir de itinerarios interesantes en un barrio universitario.

La historia de una universidad emblemática, modelo de urbanismo universitario y de recuperación patrimonial evidenciada en este libro, además de motivadora, es un discurso enriquecedor que invita a recordar la importancia que han tenido y tienen las universidades en el nacimiento y la consolidación de los centros históricos en el mundo y, por ende, de apropiación de estos centros vivos, teniendo como punto de partida el vínculo patrimonial que une la comunidad académica con la ciudadana. Además de ser una oportunidad de educación patrimonial, es importante fortalecer el sentido de identidad que une a ambos actores con su ciudad y su historia. 